\title{
Whole breast irradiation vs. APBI using multicatheter brachytherapy in early breast cancer - simulation of treatment costs based on phase 3 trial data
}

\author{
Aleksandra Harat, PhD', Maciej Harat, MD², Prof. Roman Makarewicz, MD, PhD³ \\ 'Department of Public Health, Collegium Medicum in Bydgoszcz, Nicolaus Copernicus University in Torun, Poland, 2Radiotherapy Department, \\ Oncology Center, Bydgoszcz, ${ }^{3}$ Department of Oncology and Brachytherapy, Collegium Medicum in Bydgoszcz, Nicolaus Copernicus University \\ in Torun, Poland
}

\begin{abstract}
Purpose: A recent large phase 3 trial demonstrated that the efficacy of accelerated partial-breast irradiation (APBI) in the treatment of early breast cancer is non-inferior to that of whole breast irradiation (WBI) commonly used in this indication. The aim of this study was to compare the costs of treatment with APBI and WBI in a population of patients after conserving surgery for early breast cancer, and to verify if the use of APBI can result in direct savings of a public payer.

Material and methods: The hereby presented cost analysis was based on the results of GEC-ESTRO trial. Expenditures for identified cost centers were estimated on the basis of reimbursement data for the public payer. After determining the average cost of early breast cancer treatment with APBI and WBI over a 5-year period, the variance in this parameter resulting from fluctuations in the price per single procedure was examined on univariate sensitivity analysis. Then, incremental cost-effectiveness ratio (ICER) was calculated to verify the cost against clinical outcome. Finally, a simulation of public payer's expenditures for the treatment of early breast cancer with APBI and WBI in 2013 and 2025 has been conducted.

Results: The average cost of treatment with APBI is lower than for WBI, even assuming a potential increase in the unit price of the former procedure. There was no additional health benefit of WBI and the calculation of cost-effectiveness was based on the absolute difference in overall local control rate. However, this difference $(0.92 \%$ vs. $1.44 \%)$ was fairly minimal and was not identified as statistically significant during 5 years.

Conclusions: The use of APBI as an alternative to WBI in the treatment of early breast cancer would substantially reduce healthcare expenditures in both 2013 and 2025, even assuming an increase in the price per single APBI procedure.
\end{abstract}

Key words: APBI, breast cancer, cost analysis, interstitial.

\section{Purpose}

Breast cancer is the second most common malignancy worldwide, in the vast majority of cases diagnosed at early clinical stages [1,2]. Due to high incidence of breast cancer, its treatment is consuming a substantial proportion of oncology budgets. Currently, aside from surgical treatment, the management of breast cancer is based on radiotherapy, which should be offered to all patients after breast conserving surgeries [3]. The most commonly used technique of adjuvant radiotherapy is external beam $3 \mathrm{D}$ whole breast irradiation (3D-WBI). However, other techniques, such as intensity-modulated radiation therapy (IMRT), proton beam therapy, and accelerated partial-breast irradiation (APBI) are increasingly implemented to reduce early and late toxicity of the treatment and shorten its duration. The list of techniques used for accelerated partial-breast irradiation includes APBI with 3D-CRT, or IMRT, APBI using interstitial brachytherapy, or balloon brachytherapy and intraoperative APBI (IORT).

Although considered an interesting concept, APBI is still not used routinely, mostly due to inconclusive results of randomized clinical trials [4,5]. Until recently, we lacked convincing evidence from a large patient population regarding efficacy and safety profile of this treatment. Consequently, in line with the recommendations of the American Society of Radiation Oncology, the use of APBI is limited solely to a subset of patients who are satisfy with strict clinical and pathological criteria $[6,7]$. However, the recently published 5-year results of
Address for correspondence: Aleksandra Harat, PhD, Department of Public Health, Collegium Medicum in Bydgoszcz, Nicolaus Copernicus University in Torun, Bydgoszcz, Sandomierska Street 16,

85-830 Bydgoszcz, Poland, phone: +48 668359 607, e-mail: ola.harat@cm.umk.pl
Received: 02.09 .2016

Accepted: 19.12 .2016

Published: 30.12 .2016 
3D-WBI and APBI using interstitial brachytherapy in a large population of patients with early breast cancer suggest that both methods have non-inferior efficacy in terms of local control, and differ primarily in terms of their invasiveness, potential adverse effects, and treatment duration [8].

Selection of a treatment method should be based not only on its clinical outcomes but also on reliable cost-effectiveness data. Consequently, the aim of this study was to compare the costs of treatment with APBI and WBI in a population of patients after conserving surgery for early breast cancer, and to verify if the use of APBI can result in direct savings.

\section{Material and methods}

In this study, we compared the costs of early breast cancer treatment with APBI and WBI from the public payer's perspective. The study is centered in the Polish health system.

Material for the analysis, namely the data of the number of patients, incidence of adverse effects and character thereof, recurrences, their type and treatment, duration of treatment, and clinical efficacy were extracted from the results of a multicenter international randomized phase 3 trial, GEC-ESTRO [8].

\section{Cost analysis}

\section{Cost minimization analysis}

The following were identified as the cost centers based on the results of the randomized trial mentioned above: 1 . WBI procedure (along with patients' accommodation during the treatment); 2. APBI procedure (with patients' accommodation); 3. management of local recurrences (mastectomy, lumpectomy, systemic therapy); 4. management of side effects (subcutaneous tissue effects, severe fibrosis); 5. mammography (including mammographies performed during history taking and physical examination $[\mathrm{H \& P}]$ visits); 6. follow-up H\&P visits.

The analysis did not include the costs of primary treatment, i.e. surgery, as well as the costs of systemic therapy, i.e. chemotherapy and hormonal therapy. All the costs were estimated based on reimbursement data provided by the administrative offices at the Oncology Center in Bydgoszcz. The protocol of WBI subjected to the analysis included whole breast irradiation with $42.5 \mathrm{~Gy}$ in 17 fractions, along with a $10 \mathrm{~Gy}$ boost (5 fractions) to the tumor area. Accelerated hypofractionated schemes was not inferior to standard WBI $[9,10]$, hence to those protocols are routinely implemented in numerous oncology centers. In Poland, WBI is administered in one out of the three following settings: 1 . as an inpatient treatment, lasting for 27 days on average (this period includes also a time necessary for treatment planning); 2 . as an outpatient treatment with accommodation of the patient at a hotel (reimbursed by the payer), lasting for 22 days of average; and 3. as an outpatient treatment without the patient's accommodation. Relative contribution of the abovementioned options to the analyzed cost model was estimated based on ac- commodation data for patients who have been treated at the Center of Oncology in Bydgoszcz in 2015.

The analyzed scenario of APBI included administration of $34 \mathrm{~Gy}$ in 10 fractions, twice a day during a 5-day hospital stay. Also, the costs of CT scans (not qualified as the cost of APBI in Poland) were included. Interstitial brachytherapy is an invasive procedure that could be performed as open or closed technique [11], and as such requires an anesthesia. In the hereby presented analysis, the costs of anesthesiologist's consultation, pre-procedure examination (electrocardiography, blood testing), and anesthesia itself were considered as the components of brachytherapy price, and therefore, did not represent an additional expenditure from the payer's perspective.

For the purposes of the hereby presented analysis, we assumed that the costs of mammography included also physical examination and history taking. We assumed that mammography was performed every six months during the first year of treatment and once a year thereafter. Moreover, seven additional H\&P visits per patient were included in the model $[7,12]$.

After determining the cost per procedure, we identified all cost centers quantitatively [8]. This enabled us to calculate the total costs of treatment in both groups of patients (APBI $n=633$, WBI $n=551$ ) over a 5 -year period, along with the average treatment cost per patient.

\section{Sensitivity analysis}

Taking into account the ongoing modification of healthcare service pricing strategy in Poland, we decided to conduct a univariate sensitivity analysis for the APBI and WBI prices. We analyzed the variance in the average cost of treatment resulting from a $20 \%$ change in the price of a single APBI or WBI procedure.

\section{Cost effectiveness analysis}

Cost-effectiveness analysis was based on the values of incremental cost-effectiveness ratio (ICER), calculated from the formula: (Cost $\mathrm{WBI}_{-}-\mathrm{Cost}_{A P B} / \mathrm{Outcome} \mathrm{WBI}_{\mathrm{WB}}-\mathrm{Outco}-$ $\left.m e_{A P B I}\right)[9,10,11]$. The outcome was defined as an overall local control rate at 5 -years $(98.56 \%$ for APBI and $99.08 \%$ for WBI) [8].

\section{Simulation of payer's expenditures for the treatment of early breast cancer with APBI and WBI in 2013 and 2025}

To complement the cost analyses, a simulation of payer's expenditures for the treatment of early breast cancer with APBI and WBI in 2013 and 2025 has been conducted as well. The most recent data from the National Cancer Registry regarding breast cancer incidence in Poland originate from 2013. Total number of patients aged 40 to $85+$ years who have been diagnosed with C50 in 2013 equaled 16,248 [13]. In the previously mentioned phase 3 randomized trial [8], the efficacy of APBI and WBI have been estimated for early breast cancer, which represents ca. $60 \%$ of all the diagnosed cases of this malignancy [2]. Based on the inclusion criteria of the abovementioned phase 3 trial 
[8], we assumed that $30 \%$ of patients diagnosed with early breast cancer were not eligible for brachytherapy due to technical reasons [14]. Based on these assumptions, the size of the population used to determine the treatment costs in 2013 has been defined as 6,824 patients.

We selected 2025 as an endpoint of the simulation. Assuming projected $20 \%$ increase in the incidence of breast cancer [15], a total of 8,189 patients were included. The simulation was based on the results of a univariate sensitivity analysis.

All the hereby presented costs were estimated in PLN and converted to EUR using a conversion rate for January $7^{\text {th }}, 2016(1 \mathrm{EUR}=4.3475$ PLN $)$.

\section{Results}

\section{Cost minimization analysis}

The numbers of APBI and WBI procedures, costs per procedure and total treatment costs per patient group are summarized in Tables 1 and 2.

Cost minimization analysis demonstrated that over a 5-year period, the mean cost of treatment of early breast cancer with APBI per 1 patient was 1,453.8 EUR (34\%) lower than in the case of WBI. Irrespective of the treatment method, it was the price per procedure, which constituted the principal component of the treatment cost structure and had the greatest contribution to the out- come of the analysis. Another substantial component of the cost structure was the average cost of hospital stay, higher for WBI (789.4-968.8 EUR) than for APBI (299 EUR). In the cheapest scenario, in which all patients subjected to WBI were treated in an outpatient setting, mean cost of the treatment amounted to 3,990.5 EUR and was still 1,199.6 EUR (30.1\%) higher than for APBI.

\section{Univariate sensitivity analysis}

Univariate sensitivity analysis revealed that even assuming the stable cost of WBI and a $20 \%$ increase in the price per single APBI procedure, the latter still would be cheaper. The difference in the treatment costs for both methods would be reduced to a minimum, assuming an increase in the price of APBI and a simultaneous decrease in the WBI price (Table 3).

\section{Cost-effectiveness analysis}

Low value of cost-effectiveness ratio (CER) for APBI implies that this method had a higher cost-effectiveness. However, it was WBI, which provided higher, although insignificantly, local control rate. Therefore, we calculated incremental cost-effectiveness ratio (ICER). Positive ICER value for WBI reflects an extra cost of achieving the additional clinical benefit documented during the source randomized trial (Table 4).

Table 1. Cost analysis for treatment of early breast cancer with whole breast irradiation with boost over a 5 -year period (all costs expressed in EUR)

\begin{tabular}{|c|c|c|c|c|}
\hline Procedure & $\begin{array}{c}\text { Number } \\
\text { of procedures }(n=551)\end{array}$ & $\begin{array}{l}\text { Unit cost } \\
\text { of procedure }\end{array}$ & $\begin{array}{c}\text { Total cost } \\
\text { of procedure }\end{array}$ & Percentage share \\
\hline Whole breast irradiation & 551 & $3,815.5$ & $2,102,340.5$ & $89.89 \%$ \\
\hline Inpatient care (av. over 27 days) & 55 & 968.8 & 53,284 & $2.28 \%$ \\
\hline $\begin{array}{l}\text { Outpatient care - accommodation at } \\
\text { the hotel (av. over } 22 \text { days) }\end{array}$ & 110 & 789.4 & $86,835.1$ & $3.71 \%$ \\
\hline $\begin{array}{l}\text { Outpatient care - accommodation not } \\
\text { included }\end{array}$ & 386 & 0 & 0 & 0 \\
\hline \multicolumn{5}{|l|}{ Treatment of recurrence } \\
\hline Mastectomy & - & - & - & - \\
\hline Lumpectomy & 4 & 374.9 & 1,499.6 & $0.06 \%$ \\
\hline Systemic therapy & 4 & 248.4 & 993.6 & $0.04 \%$ \\
\hline \multicolumn{5}{|l|}{ Treatment of side effects } \\
\hline Grade 2-3 subcutaneous effects & 35 & 30.3 & $1,060.5$ & $0.05 \%$ \\
\hline Severe fibrosis & 1 & 26.6 & 26.6 & $0.001 \%$ \\
\hline \multicolumn{5}{|l|}{ Follow-up } \\
\hline H\&P + mammography & 3,306 & 17.7 & $58,516.2$ & $2.50 \%$ \\
\hline \multirow[t]{3}{*}{$H \& P$} & 3,857 & 8.9 & $34,327.3$ & $1.47 \%$ \\
\hline & & Total cost & $2,338,883.4$ & $100 \%$ \\
\hline & & $\begin{array}{l}\text { Mean cost per } \\
1 \text { patient }\end{array}$ & $4,244.7$ & \\
\hline
\end{tabular}

H\&P - history taking and physical examination 
Table 2. Cost analysis for treatment of early breast cancer with accelerated partial breast irradiation using sole interstitial multicatheter brachytherapy over a 5-year period (all costs expressed in EUR)

\begin{tabular}{|c|c|c|c|c|}
\hline Procedure & $\begin{array}{c}\text { Number } \\
\text { of procedures }(n=633)\end{array}$ & $\begin{array}{l}\text { Unit cost } \\
\text { of procedure }\end{array}$ & $\begin{array}{c}\text { Total cost } \\
\text { of procedure }\end{array}$ & Percentage share \\
\hline APBI & 633 & $2,235.8$ & $1,415,236.4$ & $80 \%$ \\
\hline Inpatient care (av. over 5 days) & 633 & 299 & 189,267 & $10.71 \%$ \\
\hline CT & 633 & 81.9 & $51,842.7$ & $2.93 \%$ \\
\hline \multicolumn{5}{|l|}{ Treatment of recurrence: } \\
\hline Mastectomy & 1 & 442.3 & 442.3 & $0.03 \%$ \\
\hline Lumpectomy & 2 & 374.9 & 749.8 & $0.04 \%$ \\
\hline Systemic therapy & 4 & 248.4 & 993.6 & $0.06 \%$ \\
\hline \multicolumn{5}{|l|}{ Treatment of side effects: } \\
\hline Grade 2-3 subcutaneous effects & 48 & 30.3 & $1,454.4$ & $0.08 \%$ \\
\hline Severe fibrosis & 0 & - & - & - \\
\hline \multicolumn{5}{|l|}{ Follow-up: } \\
\hline H\&P + mammography & 3,798 & 17.7 & $67,224.6$ & $3.81 \%$ \\
\hline \multirow[t]{3}{*}{$H \& P$} & 4,431 & 8.9 & $39,435.9$ & $2.23 \%$ \\
\hline & & Total cost & $1,766,646.7$ & $100 \%$ \\
\hline & & $\begin{array}{c}\text { Mean cost per } \\
1 \text { patient }\end{array}$ & $2,790.9$ & \\
\hline
\end{tabular}

APBI - accelerated partial breast irradiation; CT - computed tomography; H\&P - history taking and physical examination

Table 3. Results of univariate sensitivity analysis for treatment of early breast cancer with APBI and WBI (assumed a 20\% increase/decrease in the price per single procedure)

\begin{tabular}{lccc} 
& \multicolumn{3}{c}{ Average treatment cost } \\
\cline { 2 - 4 } & Stable cost per procedure & 20\% increase in the unit cost & 20\% decrease in the unit cost \\
\hline APBI & $2,790.9$ & $3,238.1$ & $2,343.8$ \\
\hline WBI & $4,244.7$ & $5,007.9$ & $3,481.7$
\end{tabular}

$A P B I$ - accelerated partial breast irradiation; WBI - whole breast irradiation

Table 4. Incremental analysis for treatment of early breast cancer with WBI and APBI

\begin{tabular}{|c|c|c|c|c|}
\hline Treatment method & $\begin{array}{l}\text { Average treatment cost } \\
\text { (EUR) }\end{array}$ & Effect (local control rate) & CER & $\begin{array}{l}\text { ICER for WBI } \\
\text { (EUR per \%) }\end{array}$ \\
\hline WBI & $4,244.7$ & 99.08 & 42.84 & $2,795.77$ \\
\hline APBI & $2,790.9$ & 98.56 & 28.31 & \\
\hline
\end{tabular}

$A P B I$ - accelerated partial breast irradiation; WBI - whole breast irradiation

\section{Simulation of payer's expenditures for the treatment of early breast cancer with APBI and WBI in 2013 and 2025}

Simulations of annual expenditures of the public payer for the treatment of early breast cancer with both methods for three different procedure pricing scenarios are presented in Table 5.

Based on breast cancer incidence data for 2013 and average treatment costs (Table 3), the use of APBI as an alternative to WBI in the management of patients with early breast cancer satisfying the inclusion criteria of the GEC-ESTRO study, would result in the following reduction of the public payer's annual expenditures:

- by $9,920,731$ EUR - assuming a stable price per single APBI procedure,

- by $12,077,116$ EUR - assuming a $20 \%$ increase in the price per APBI procedure,

- by 7,765,030 EUR - assuming a $20 \%$ decrease in the price per APBI procedure. 
Table 5. Simulation of public payer's expenditures in 2013 and 2025 for the treatment of early breast cancer with APBI and WBI in the population of women aged 40 to $85+$ years, assuming a $20 \%$ increase/decrease in the price per single procedure (in EUR)

\begin{tabular}{lcccccc} 
Year/patient & \multicolumn{4}{c}{ APBI } & & WBI \\
\cline { 2 - 5 } number & $\begin{array}{c}\text { Stable cost } \\
\text { per procedure }\end{array}$ & $\begin{array}{c}\text { Increase } \\
\text { in the unit cost }\end{array}$ & $\begin{array}{c}\text { Decrease } \\
\text { in the unit cost }\end{array}$ & $\begin{array}{c}\text { Stable cost } \\
\text { per procedure }\end{array}$ & $\begin{array}{c}\text { Increase } \\
\text { in the unit cost }\end{array}$ & $\begin{array}{c}\text { Decrease } \\
\text { in the unit cost }\end{array}$ \\
\hline $2013, n=6,824$ & $19,045,102$ & $22,096,794$ & $15,994,091$ & $28,965,833$ & $34,173,910$ & $23,759,121$ \\
\hline $2025, n=8,189$ & $22,854,680$ & $26,516,800$ & $19,193,378$ & $34,759,848$ & $41,009,693$ & $28,511,641$
\end{tabular}

$A P B I$ - accelerated partial breast irradiation; WBI - whole breast irradiation

In assuming of further increase of breast cancer incidence, the application of APBI in breast cancer patients treated in 2025 would result in the following savings:

- 11,905,168 EUR - assuming a stable price per single APBI procedure,

- 14,492,893 EUR - assuming a 20\% increase in the price per APBI procedure,

- 9,318,263 EUR - assuming a 20\% decrease in the price per APBI procedure.

The difference in the payer's expenditures would be the lowest in case of an increase in the price per APBI procedure, and simultaneous decrease in the WBI price. In this scenario, the expenditures for treatment with APBI still would be lower but the difference would amount to only 1,662,327 EUR for 2013 and to 1,994,841 EUR for 2025.

\section{Discussion}

Cost minimization analysis demonstrated that the average treatment cost of early breast cancer with APBI is lower than for WBI. This resulted primarily from the difference in the price per single procedure. Irrespective of the method, the price per procedure contributed to more than $3 / 4$ of the total treatment cost; however, the price per single WBI procedure was $41.4 \%$ higher as compared to the APBI price.

Since APBI was identified as a less costly method both during cost minimization analysis and based on CER values, and GEC-ESTRO study revealed that WBI results in lower 5 -year recurrence rate $(0.92 \%$ for WBI vs. $1.44 \%$ for APBI) [8], we have calculated the incremental cost-effectiveness ratio. Based on the ICER value, the additional health benefit produced by WBI was associated with an extra cost of 2,795.77 EUR per \%.

However, the difference in 5-year local recurrence rates for WBI and APBI was not statistically significant $(p=0.42)$ [8], and consequently, ICER was not an obligatory component of the analysis. Nonetheless, we have calculated this parameter similarly to previously published studies $[16,17,18]$. Our findings imply that APBI was equally efficacious as WBI and generated lower treatment cost over a 5-year period. As demonstrated in the payer's expenditure simulation, the use of APBI may result in substantial savings for the public healthcare system. Assuming stable price of both procedures, the use of APBI as an alternative to WBI would reduce public payer's expenditures in 2013 by $9,920,731$ EUR, which corresponds to $5.7 \%$ of the overall value of contracts for radiotherapy in this year [19].
Aside from the price per procedure, $\mathrm{APBI}$ and WBI differed substantially in terms of the cost of patients' accommodation, derived from the number of days of hospital/hotel stay. Even supposing the treatment of all patients qualified for WBI in an outpatient setting, the average treatment cost with this method would be greater than for the application of APBI in an inpatient setting. The lowest difference in the average treatment cost would be achieved if the price per single APBI procedure increased simultaneously to a decrease in the WBI price; however, even under such circumstances, the average treatment cost for APBI would be 7\% lower (Table 3).

In the hereby presented analysis, we assumed that the price per either procedure may change; this supposition resulted from the ongoing modification of healthcare service pricing strategy in Poland. The list of postulated changes includes adjustment of prices for amortization and replacement of equipment, treatment effectiveness measures, and other micro-costs [19,20]. Published experiences from other countries suggest that pricing of medical procedures can be also based on quantitative criteria. Contrary to Poland, the prices of hypofractionated radiotherapy regimens in the United States are lower, which makes them potentially preferred over the 22-to 25-fraction schemes, being currently a standard of external beam irradiation. In an American cost comparison analysis, APBI using external beam radiotherapy was shown to be less costly than WBI and APBI using brachytherapy [21]. However, the results of a randomized trial suggest that APBI using external beam radiotherapy may be associated with higher incidence of adverse cosmetic outcomes and late radiation toxicity than WBI [22]. Three protocols of APBI using hypofractionated external beam photon therapy (up to 40 Gy in 15 fractions, MRC IMPORT LOW Trial), up to $38.5 \mathrm{~Gy}$ in 10 fractions administered twice a day (Rapid Trial), and up to 30 Gy in 5 fractions (University of Florence Trial) are a subject of currently ongoing phase 3 trials. Furthermore, the hypofractionated schemes were demonstrated to be preferred by patients over more invasive alternatives [23].

Since our study covered solely a 5-year period, the hereby presented data do not include the costs generated by long-term consequences of irradiation, such as late cosmetic outcomes and late adverse effects. This with no doubt represents a drawback of this study, since many complications of early breast cancer treatment, e.g. secondary malignancies and cardiovascular toxicity, are known to manifest no earlier than after many years. How- 
ever, these possible limitations seem to be overestimated in comparison with the strengths of the present study, which clearly shows a large difference of costs. Moreover, we assumed that an optimal distribution of radiation to critical organs, being characteristic feature of interstitial APBI, is likely reflected by lesser risk of complications and consequently, lower costs of their management [24]. Furthermore, late results of APBI and WBI were previously a subject of a 12-year matched-pair analysis, which demonstrated the two methods, do not differ significantly in terms of overall survival, local and regional control rates [18].

Another potential limitation of our study may result from the fact that we did not consider actual treatment costs in individual patients but used previously published pooled data [8]. Furthermore, our analysis was not adjusted for mortality during the analyzed period. However, breast cancer specific mortality of patients included in GEC-ESTRO study did not differ significantly between the ABPI and WBI group $(p=0.84)$, and a relatively low contribution of expenditures for follow-up, management of recurrences, and adverse effects to the overall cost structure implies that inclusion of these factors would not substantially alter the outcomes of our analysis (Tables 1 and 2).

The simulation of public payer's expenditures did not include social costs, such as the amount of money spent by patients to get to an outpatient clinic and the number of working days lost through sickness absences. However, we assume that owing shorter duration of APBI treatment, this method would be preferred in the context of reducing the abovementioned costs $[25,26]$.

Currently, most of breast cancer patients qualified for irradiation are treated at radiotherapy departments, whereby WBI is one of the most commonly performed procedures. However, the results of GEC-ESTRO study comparing clinical effectiveness of APBI versus WBI, as well as the hereby presented cost-effectiveness analysis, suggest that it is the former method of treatment, which should be preferred during the allocation of healthcare resources. In an era of accelerated technological progress and growing expenditures in healthcare sector, economic analyses constitute an important instrument for decision-makers. Healthcare resources, both monetary and personal, are generally deficient, and therefore, all decisions regarding their allocation should be based on reliable clinical evidence and accurately determined costeffectiveness data.

\section{Conclusions}

The average cost of treatment with APBI is lower than for WBI, even assuming a potential increase in the unit price of the former procedure. The costs of APBI were - in all calculated scenarios (> 30\%) - significantly lower than those of WBI.

Cost-effectiveness ratio for APBI is lower than for WBI. There was no additional health benefit of WBI, and the calculation of cost-effectiveness was just based on the absolute difference in overall local control rate. However, this difference $(0.92 \%$ vs. $1.44 \%)$ was quite minimal and was not identified statistically significant at 5-years.
The use of APBI as an alternative to WBI in the treatment of early breast cancer would substantially reduce healthcare expenditures in both 2013 and 2025, even assuming an increase in the price per single APBI procedure.

\section{Disclosure}

Authors report no conflict of interest.

\section{References}

1. International Agency for Research on Cancer. Globocan 2012. Estimated Cancer Incidence, Mortality and Prevalence Worldwide in 2012. Available at: http://globocan.iarc.fr/ Default.aspx. Accessed: January 16, 2016.

2. American Cancer Society. Breast Cancer Facts and Figures, 2011-2012. American Cancer Society, Inc.; Atlanta 2011, 8.

3. Fisher B, Anderson S, Bryant J et al. Twenty-year follow-up of a randomized trial comparing total mastectomy, lumpectomy, and lumpectomy plus irradiation for the treatment of invasive breast cancer. N Engl J Med 2002; 347: 1233-1241.

4. Veronesi U, Orecchia R, Maisonneuve P et al. Intraoperative radiotherapy versus external radiotherapy for early breast cancer (ELIOT): a randomized controlled equivalence trial. Lancet Oncol 2013; 14: 1269-1277.

5. Vaidya JS, Joseph DJ, Tobias JS et al. Targeted intraoperative radiotherapy versus whole breast radiotherapy for breast cancer (TARGIT-A trial): an international, prospective, randomized, non-inferiority phase 3 trial. Lancet 2010; 10: 91-102.

6. Smith BD, Arthur DW, Buchholz TA et al. Accelerated partial breast irradiation consensus statement from the American Society for Radiation Oncology (ASTRO). Int J Radiat Oncol Biol Phys 2009; 74: 987-1001.

7. Shah C, Wobb J, Manyam B et al. Accelerated partial breast irradiation utilizing brachytherapy: patient selection and workflow. J Contemp Brachytherapy 2016; 8: 90-94.

8. Strnad V, Ott OJ, Hildebrandt G et al. 5-year results of accelerated partial breast irradiation using sole interstitial multicatheter brachytherapy versus whole-breast irradiation with boost after breast-conserving surgery for low-risk invasive and in-situ carcinoma of the female breast: a randomized, phase 3, non-inferiority trial. Lancet 2016; 387: 229-238.

9. Whelan T, Pignol J, Levine $\mathrm{M}$ et al. Long-term results of hypofractionated radiation therapy for breast cancer. $N$ Engl J Med 2010; 362: 513-520.

10. The START Trialists' Group. The UK Standardization of Breast Radiotherapy (START) Trial B of radiotherapy hypofractionation for treatment of early breast cancer: a randomized trial. Lancet 2008; 371: 1098-1107.

11. Gurram L, Wadasadawala T, Joshi K et al. Multi-catheter interstitial brachytherapy for partial breast irradiation: an audit of implant quality based on dosimetric evaluation comparing intra-operative versus post-operative placement. J Contemp Brachytherapy 2016; 8: 116-121.

12. Jassem J, Duchnowska R, Kawecki A et al. Badania kontrolne po leczeniu w najczęstszych nowotworach litych u dorosłych. NOWOTWORY Journal of Oncology 2014; 64: 415-435.

13. Wojciechowska U, Didkowska J. Zachorowania i zgony na nowotwory złośliwe w Polsce. Krajowy Rejestr Nowotworów, Centrum Onkologii - Instytut im. Marii Skłodowskiej-Curie. Available at: http://onkologia.org.pl/raporty/ Accessed: January 16, 2016.

14. Polgár C, Fodor J, Major T et al. Breast-conserving therapy with partial or whole breast irradiation: Ten-year results of the Budapest randomized trial. Radiother Oncol 2013; 108: 197-202. 
15. Didkowska J, Wojciechowska U, Zatoński W. Prediction of cancer incidence and mortality in Poland up to the year 2025. Cancer registration, Krajowy Rejestr Nowotworów, Centrum Onkologii - Instytut im. Marii Skłodowskiej-Curie 2009: 4549 [in Polish].

16. Stokes ME, Thompson D, Montoya EL et al. Ten-year survival and cost following breast cancer recurrence: estimates from SEER-Medicare data. Value Health 2008; 11: 213-220.

17. Shah C, Badiyan S, Khwaja S et al. Evaluating radiotherapy options in breast cancer: does intraoperative radiotherapy represent the most cost - efficacious option? Clinical Breast Cancer 2014; 14: 141-146.

18. Shah C, Antonucci JV, Wilkinson JB et al. Twelve-year clinical outcomes and patterns of failure with accelerated partial breast irradiation versus whole-breast irradiation: results of a matched-pair analysis. Radiother Oncol 2011; 100: 210-214.

19. Gryglewicz J, Gałązka-Sobotka M, Gierczyński J et al. Finansowanie świadczeń z zakresu radioterapii $\mathrm{w}$ latach 20112013. Instytut Zarządzania w Ochronie Zdrowia Uczelni Łazarskiego; Warszawa 2014: 10-11, 126-129 [in Polish].

20. Smaga A, Mikułowska M, Komorowska A et al. Rak piersi w Polsce - leczenie to inwestycja. Sequence HC Partners; Warszawa 2014:5-6 [in Polish].

21. Lanni T, Keisch M, Shah C et al. A cost comparison analysis of adjuvant radiation therapy techniques after breast-conserving surgery. Breast J 2013; 19: 162-167.

22. Olivotto IA, Whelan TJ, Parpia S et al. Interim cosmetic and toxicity results from RAPID: a randomized trial of accelerated partial breast irradiation using three-dimensional conformal external beam radiation therapy. J Clin Oncol 2013; 31: 4038-4045.

23. Hoopes DJ, Kasziska D, Chapin P et al. Patient preferences and physician patterns regarding breast radiotherapy. Int J Radiat Oncol Biol Phys 2012; 82: 674-681.

24. Sato K, Mizuno Y, Fuchikami H et al. Comparison of radiation dose to the left anterior descending artery by whole and partial breast irradiation in breast cancer patients. J Contemp Brachytherapy 2015; 7: 23-28.

25. Suh WW, Pierce LJ, Vicini FA et al. A cost comparison analysis of partial versus whole-breast irradiation after breast-conserving surgery for early-stage breast cancer. Int J Radiat Oncol Biol Phys 2005; 62: 790-796.

26. Suh WW, Hillner BE, Pierce LJ et al. Cost-effectiveness of radiation therapy following conservative surgery for ductal carcinoma in situ of the breast. Int J Radiat Oncol Biol Phys 2005; 61: 1054-1061. 